УДК 547.972

\title{
ФЛАВОНОИДЫ EQUISETUM ARVENCE L. И LATHYRUS PRATENSIS L.
}

\author{
() В.М. Боначева", А.А. Дренин, Э.Х. Ботиров \\ Сургутский государственный университет, ул. Ленина, 1, Сургут, 628412 \\ (Россия), e-mail: bwmbeml@mail.ru
}

Изучены флавоноиды надземных частей Equisetum arvense L. (хвощ полевой) и Lathyrus pratensis L. (чина луговая), произрастающих на территории Ханты-Мансийского автономного округа. Из надземной части хвоща полевого выделены лютеолин, лютеолин-7-O- $\beta$-D-глюкопиранозид, лютеолин-4'-O- $\beta$-D-глюкопиранозид, а из чины луговой лютеолин-7-O- $\beta$-D-глюкопиранозид, лютеолин-4'-O- $\beta$-D-глюкопиранозид и кверцетин-3-O- $\beta$-D-глюкопиранозид. Полученные соединения идентифицированы на основании химических превращений и результатов изучения данных ИК-,

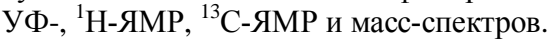

Ключевые слова: Equisetum arvense (L.) Smeet - хвощ полевой, и Lathyrus pratensis L. - чина луговая, флавоноиды, лютеолин, лютеолин-7-O- $\beta$-D-глюкопиранозид, лютеолин-4'-O- $\beta$-D-глюкопиранозид, $\quad$ кверцетин-3-O- $\beta$-Dглюкопиранозид.

\section{Введение}

Среди многообразия флоры Западной Сибири вызывают интерес растения, содержащие флавоноиды. Большинство флавоноидов способны уменьшать хрупкость и проницаемость стенок капилляров. В настоящее время на основе флавоноидов созданы препараты с выраженной противовоспалительной, противоязвенной, диуретической, гипогликемической, желчегонной, гепатопротекторной активностью. В последние годы появились сообщения об их противоопухолевом и антивирусном действии $[1,2]$.

Хвощ полевой (Equisetum arvense L. семейств Equisetaceae) - многолетнее травянистое споровое растение, имеет космополитический тип ареала. Это самый распространенный вид хвоща, произрастающий в нашей стране почти повсюду [3].

Хвощ полевой как лекарственное растение используют не только в народной, но и в официальной медицине для лечения многих заболеваний. Такое многостороннее действие растения, по-видимому, обусловлено его богатым химическим составом. В нем найдены сапонины, алкалоиды, дубильные вещества, смолы, горечи, также обнаружена яблочная, аконитовая, кремневая и щавелевая кислоты, витамины С, В, каротин, флавоноиды и др. [3-5] .

Чина луговая (Lathyrus pratensis L., семейство Fabaceae) - многолетнее растение с широким ареалом распространения. Применяется в официальной и народной медицине для лечения острых и хронических респираторных заболеваний, заболеваний печени, при пневмониях и туберкулезе легких, а также при бессоннице [6].

В составе экстрактов этого растения обнаружены циклитолы, витамины, фенолкарбоновые кислоты, хиноны, а также флавоноиды и их гликозиды $[6,7]$.

С целью поиска новых биологически активных веществ нами изучены флавоноиды надземных частей хвоща полевого и чины луговой, произрастающих на территории Ханты-Мансийского автономного округа.

Боначева Виктория Михайловна - аспирант кафедры химии, тел. (3462) 76-28-00, e-mail: bwmbeml@mail.ru,. Дренин Алексей Анатольевич - доцент кафедры химии, кандидат химических наук, тел. (3462) 7628 00, e-mail: bioecologist@yandex.ru.

Ботиров Эркин Хожиакбарович - заведующий кафедрой химии, профессор, тел. (3462) 7630 91, e-mail: botirov-nepi@mail.ru,

\section{Методика исследования}

Экстракция и выделение флавоноидов из надземной части хвощза полевого. Воздушно-сухую измельченную надземную часть хвоща полевого (900 г), собранного на территории Сургутского района ХМАО летом в 2009 г., пятикратно экстрагиро-

\footnotetext{
* Автор, с которым следует вести переписку.
} 
вали 85\%-ным этиловым спиртом при комнатной температуре. Объединенный экстракт сгущали в вакууме, разбавляли водой в соотношении $1: 1$ и затем последовательно обрабатывали на делительной воронке петролейным эфиром, хлороформом, этилацетатом и $н$-бутанолом.

Хроматографированием этилацетатной фракции хвоща полевого (10,5 г) на колонке $(90 \times 3,5$ см) с силикагелем (210 г) в градиентной системе этилацетат-этанол выделили три вещества, которые относятся к группе флавоноидов. Вещество 1 (выход 0,30 г) элюировано смесью растворителей - этанол в соотношении $98: 2$, вещество 2 (выход 0,40 г) - элюировано системой растворителей этилацетат - этанол (94:6), вещество 3 (выход 0,45 г) - этой же системой $(92: 8)$. Полученные вещества очищены колоночной хроматографией на полиамиде марки «Woelm» (Германия) в градиентной системе растворителей хлороформ - этанол.

Экстракиия и выделение флавоноидов из надземной части чины луговой. Сбор растительного материала проводился в июле 2007 г., в Сургутском районе.

Воздушно-сухую навеску $(763,9$ г) измельченного растительного материала надземной части чины луговой экстрагировали 5 л 80\%-ного этилового спирта при комнатной температуре в течение суток. Экстракт упаривали в вакууме до 0,5 л. Процедуру проводили пятикратно. Обобщенный сгущенный под вакуумом экстракт разбавляли водой $(1: 1)$ и последовательно обрабатывали на делительной воронке петролейным эфиром, хлороформом, этилацетатом, бутанолом.

Этилацетатную (8 г) и бутанольную фракцию (10 г) хроматографировали на колонках (3,5×90 см) с силикагелем (200 г) в градиенте спирта в хлороформе (0-30 и 4-35\%). Фракции собирали по 100 мл. Из этилацетатной фракции спиртового экстракта был выделены вещества 2 и 3 , а из бутанольной - соединение 4.

Полный кислотный гидролиз флавоноидных гликозидов проводили нагреванием на кипящей водяной бане с обратным холодильником раствора 10 мг вещества в 10 мл смеси 5\% соляной кислоты и этанола в соотношении $1: 1$ в течение 2 ч [5]. Осадок агликона, выпавший при отгонке этанола в вакууме, отделяли фильтрованием. Фильтрат упаривали досуха, остаток растворяли в этаноле и углеводы анализировали методом тонкослойной хроматографии в присутствии подлинных образцов моносахаридов в системе растворителей $\mu$-бутанол - уксусная кислота - вода $(6: 1,5: 2,5)$. Пластинки проявляли смесью $н$-бутанол - вода уксусная кислота - фосфорная кислота - анилин - дифениламин, мл (60 - 25-15-10 - 1 - 2 г), высушивали в термостате при $120^{\circ} \mathrm{C}$ в течение 5 мин [6].

УФ-спектры регистрировали на спектрофотометре СФ-2000 в очищенном этаноле, ИК-спектры снимали на ИК-Фурье-спектрометре IR Prestige-21. Масс-спектры снимали на хромато-масс-спектрометре Thermo Finnigan MAT 95 XР, энергия ионизации 70 эВ. Спектры ЯМР ${ }^{1} \mathrm{H}$ и ${ }^{13} \mathrm{C}$ регистрировали на спектрометрах «Bruker AM-300», «Bruker AMX III-300» (300,13 МГц $\left({ }^{1} \mathrm{H}\right), 75,47$ МГц $\left.\left({ }^{13} \mathrm{C}\right)\right)$, внутренний стандарт ТМС. Химические сдвиги приведены в миллионных долях (м.д.) в $\delta$-шкале.

Температуры плавления определяли на столике Кофлера.

Для ТСХ использовали пластинки Sorbfil ПТСХ-П-А-УФ. Пятна флавоноидов на пластинках просматривали в ультрафиолете в хроматографическом облучателе УФС-254/365 при 254 и 365 нм, а также обнаруживали проявлением 3\%-ным спиртовым раствором ванилина в смеси с концентрированной соляной кислотой в соотношении $4: 1$ и 1\%-ным спиртовым раствором $\mathrm{AlCl}_{3}$. Колоночную хроматографию проводили на силикагеле марки КСК 100/160 мкм.

\section{Результаты и обсуждение}

Выделенные индивидуальные соединения относятся к классу флавоноидов. Идентификацию полученных веществ проводили на основании результатов химических превращений и спектральных данных. Полученные результаты сравнивали с литературными данными.

Лютеолин (1) - светло-желтое кристаллическое вещество состава $\mathrm{C}_{15} \mathrm{H}_{10} \mathrm{O}_{6}, \mathrm{~T}_{\text {пл. }} 327-329{ }^{\circ} \mathrm{C}$. По данным УФ-спектроскопии данное вещество относится к производным флавона (максимумы поглощения 250, 270,356 нм). На основании изучения УФ-спектров, снятых в присутствии диагностических реагентов, установили наличие фенольных гидроксильных групп в положениях 5,7,4' [8].

В ИК-спектре исследуемого соединения наблюдаются полосы колебаний гидроксильных групп (3450-3200 см $\left.{ }^{-1}\right)$, карбонил $\gamma$-пирона $\left(1658 \mathrm{~cm}^{-1}\right)$, ароматических ядер $\left(1612 \mathrm{~cm}^{-1}\right)$.

В спектре ПМР соединения, снятого в дейтерированном диметилсульфоксиде, наблюдаются сигналы протонов 5,7,3',4'-тетразамещенного флавона. 


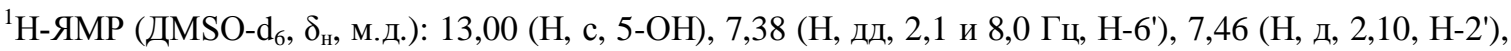
6,82 (Н, д, 8,2 Гц, Н-5'), 6,35 (1Н, д, 1,5 Гц, Н-8), 6,09 (1Н, д, 1,7 Гц, Н-6), 6,57 (1Н, с, Н-3).

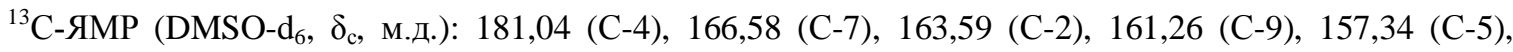
151,40 (C-4'), 146,16 (C-3'), 120,06 (C-1'), 118,86 (C-6'), 115,81 (C-5'), 112,45 (C-2'), 102,53 (C-10), 101,92 (C3), 99,29 (С-6), 94,10 (С-8).

Исходя из полученных данных, соединение идентифицировано с 5,7,3',4'-тетрагидроксифлавоном (лютеолином). Выводы подтверждаются также непосредственным сравнением флавона с подлинным образцом лютеолина (ТСХ, ИК-спектр).

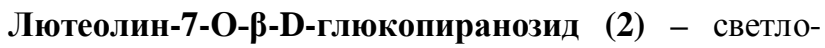
желтые кристаллы с $\mathrm{T}_{\text {пл. }} 239-241{ }^{\circ} \mathrm{C}$, состава $\mathrm{C}_{21} \mathrm{H}_{20} \mathrm{O}_{10}, \mathrm{M}^{+}$ агликона 270. УФ-спектр данного соединения имеет максимумы поглощения при длине волны 271, 340 нм, что характерно для флавонов [8]. При добавлении ацетата натрия к раствору вещества сдвиги не происходят (271, 340 нм), поэтому 7-ОН-замещена. С гидроксидом натрия наблюдаем батохромный сдвиг полосы I на 44 нм, полосы II на 8 нм, следовательно, молекула содержит свободные фенольные гидроксильные группы. С $\mathrm{AlCl}_{3}-271,290,382$ нм.

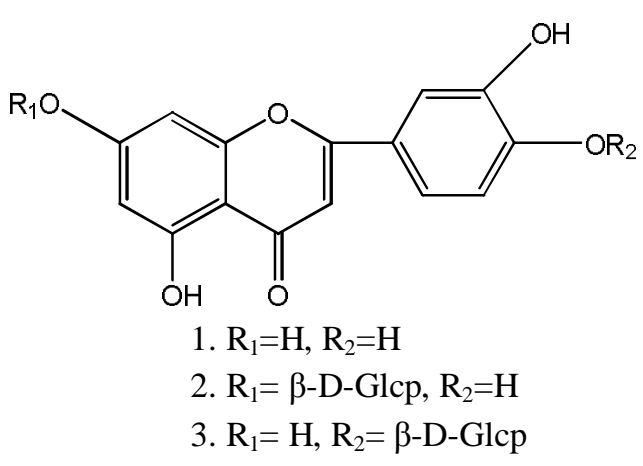

В ИК-спектре наблюдаются полосы колебаний гидроксильных групп (3515,52-3068,32 см $\left.{ }^{-1}\right)$, карбонил $\gamma$-пирона $\left(1657,12 \mathrm{~cm}^{-1}\right)$, ароматических $\mathrm{C}=\mathrm{C}$ связей $\left(1502,20 \mathrm{~cm}^{-1}\right), \mathrm{C}-\mathrm{O}$-гликозидные колебания $\left(1078,77-1031,76 \mathrm{~cm}^{-1}\right)$ и др.

Был проведен полный кислотный гидролиз вещества смесью 5 мл 5\%-ной $\mathrm{HCl}$ и этанол $(1: 1)$ в течение 2 ч. В результате получили лютеолин и D-глюкозу. Продукты гидролиза идентифицировали, используя метод ТСХ.

B ${ }^{1} \mathrm{H}$-ЯMP-спектре (DMSO-d 6 ): проявляются сигналы 7,5,3',4'-тетразамещенного флавона и углеводной части при 12,90 (1Н, уш. с, 5-OH), 10,80 (1Н, уш. с., 4'-OH), 9,11 (1H, с, 3'-ОН), 7,52 (2H, д, 8,9 Гц, Н2',6'), 7,24 (2Н, д, 8,9 Гц, Н-5'), 6,83 (1Н, с, Н-3), 6,50 (1Н, д, 2 Гц, Н-8), 6,20 (1Н, д, 2 Гц, Н-6), 4,99 (1Н, д, 7,3 Гц, H-1"Glc), 3,17-3,49 м.д. (м, протоны сахарной части).

Сигнал аномерного протона D-глюкозы проявляется в виде дублета при 4,99 м.д. с КССВ 7,3 Гц, что свидетельствует о $\beta$-конфигурации гликозидной связи.

${ }^{13} \mathrm{C}-9$ МР (ДМSО-d $6, \delta_{\mathrm{c}}$, м.Д.): 181,81 (C-4), 164,31 (C-7), 163,21 (C-2), 161,47 (C-9), 157,38 (C-5), 148,57 (C-4'), 146,93 (C-3'), 124,71 (C-1'), 118,56 (C-6'), 116,00 (C-5'), 113,61 (C-2'), 104,00 (C-10), 103,82 (C3), 101,18 (C-1"), 98,95 (C-6), 94,06 (C-8), 77,33 (C-5"), 75,86 (C-3"), 73,26 (C-2"), 69,78 (C-4"), 60,72 (C-6").

Изучением физико-химических свойств и спектральных данных, а также сравнением с подлинным образцом исследуемое вещество идентифицировали с лютеолин-7-О- $\beta$-D-глюкопиранозидом (цинарозидом) [9].

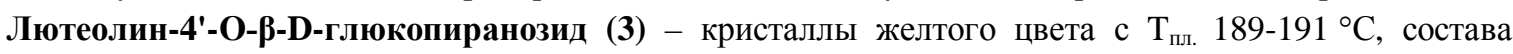
$\mathrm{C}_{21} \mathrm{H}_{20} \mathrm{O}_{10}$. УФ-спектр с $\lambda_{\max }^{\text {этанол }}: 271,290 *, 342$ нм характерен для флавонов. Смещение максимумов поглощения при добавлении ионизирующих и комплексообразующих добавок свидетельствует о наличии свободных фенольных гидроксильных групп в положениях 5 и 7, а также об отсутствии гидроксила в положении 4' (+NaOH: 270, 395 нм; + AcONa: 271, 370 нм; + $\mathrm{AlCl}_{3}: 279,351,386 *$ нм) [8].

В ИК-спектре наблюдаются полосы колебаний $\gamma$-пирона $\left(1653,1613,1591 \mathrm{~cm}^{-1}\right)$ и ароматической конденсированной системы $\left(1504,1442 \mathrm{~cm}^{-1}\right.$ ) [4]. Широкая полоса в области 3400-3200 см${ }^{-1}$ (колебания -ОН группы), полосы колебаний при 1074, 831, 806, 744 см$^{-1}$ (пиранозный цикл углевода), а также при 1258 и $1029 \mathrm{~cm}^{-1}$ (гликозидные связи) свидетельствуют, что соединение является гликозидом.

При кислотном гидролизе исследуемого вещества был получен лютеолин, и D-глюкоза.

${ }^{1}$ H-ЯMP (DMSO-d 6 , $\delta_{\mathrm{H}}$ ): H-3 (6,80 м.д., c), Н-6 (6,20 м.д., д, Ј=2,0 Гц), Н-8 (6,50 м.д., д, Ј=2,0 Гц), Н-2' (7,55 м.д., д, J=2,2 Гц), Н-5' (7,30 м.д., д, J=8,3 Гц), Н-6' (7,50 м.д., дд, J=2,2 и 8,1 Гц), Н-1', (4,90 м.д., д, J=6,9 Гц), Н-2'’-Н-6', (3,40 - 3,80 м.д., м).

${ }^{13}$ C-ЯMP (DMSO-d 6 , $\delta_{\mathrm{C}}$, м.д.): C-2 (163,26), C-3 (104,05), C-4 (181,86), C-5 (157,42), C-6 (99,00), C-7 (164,34), C-8 (94,10), C-9 (161,53), C-10 (103,89), C-1'(124,78), C-2' (113,66), C-3' (146,99), C-4' (148,61), C-5' (116,05), C-6' (118,60), C-1'” (101,25), C-2'’ (73,31), C-3'’ (75,91), C-4’’ (69,83), C-5'” (77,37), C-6’' (60,77).

Из данных спектров ${ }^{1} \mathrm{H}-$ и ${ }^{13} \mathrm{C}$-ЯМР следует, что вещество является моноглюкозидом. Положение гликозилирования установили сравнением спектров ЯМР- ${ }^{13} \mathrm{C}$ гликозида и лютеолина. В спектре глюкозида 
наблюдается диамагнитный сдвиг сигнала атома С-4' в сравнении с таковым лютеолина на 1,12 м.д., в то время как сигналы атомов C-1', C-3' и С-5' претерпевают парамагнитный сдвиг. Причем сигнал С-3' смещается в слабое поле заметно сильнее, чем C-5', что всегда наблюдается для атома углерода, связанного с гидроксильной группой, находящегося в орто-положении относительно места гликозилирования [10-12].

Таким образом, гликозид 3 идентифицирован с лютеолин-4'-O- $\beta$-D-глюкопиранозидом [7].

Кверцетин-3-О- $\beta$-D-глюкопиранозид (4) - $\mathrm{C}_{21} \mathrm{H}_{20} \mathrm{O}_{12}$, ярко-желтые кристаллы с $\mathrm{T}_{\text {пл. }} 238-239$ ' ${ }^{\circ}, \lambda_{\max }^{\text {этанол }}$ : 255, 266, 362 нм; +NaOH: 260, 270, 407 нм; +AcONa: 260, 270, 417 нм; +AlCl 3 : 265, 275, 467 Hм; +AlCl $/ \mathrm{HCl}_{2}$ 255, 266, 407 нм. ЯMP-1Н (DMSO-d 6 , бН, м.д.): 6,52 (д, 2,0 Гц, Н-6), 6,58 (д, 2,0 Гц, Н-8), 7,20 (д, 8,5 Гц, Н-5'), 7,85 (дд, 2,0 и 8,0 Гц, Н-6'), 8,14 (уш. с, Н-2'), 13,75 (уш. с, 5-ОН), 5,46 (д, 7,0 Гц, Н-1'’), 3,65-4,40 (протоны сахарной части). При кислотном гидролизе вещества 3 получены кверцетин и D-глюкоза.

В отличие от травы чины луговой, произрастающей в Узбекистане, в растении Ханты-Мансийского автономного округа лютеолин и рутин не обнаружены [7].

\section{Выводы}

Из надземной части хвоща полевого впервые выделены лютеолин-7-O- $\beta$-D-глюкопиранозид, лютеолин-4'-O- $\beta$-D-глюкопиранозид, а лютеолин обнаружен в хвоще полевом раннее. Известные два гликозида, наряду с кверцетин-3-O- $\beta$-D-глюкопиранозидом, выделены также из надземной части чины луговой.

Вышеуказанные соединения идентифицированы на основании результатов химических превращений, данных УФ-, ${ }^{1} \mathrm{H}$ и ${ }^{13} \mathrm{C}$-ЯМР, ИК-спектров.

\section{Список литературы}

1. The Science of Flavonoids. Ed. E. Grotewold. New-York: Springer Science, 2006. 273 p.

2. Flavonoids in Health and Disease. Ed. C. A Rice-Evans, L. Packer, New York, 2003. 458 p.

3. Растительные ресурсы России и сопредельных государств. Ч. 1: Семейства Lycopodiaceae - Ephedraceae. СПб, 1996. С. $12-15$.

4. Тиктинский О.Д. Лечебное действие почечного чая и полевого хвоща при мочекислом диатезе // Урология и нефрология. 1983. №1. С. 47-50.

5. Фигуркин Б.А. Диуретическая активность флавоноидов хвоща полевого // Растительные ресурсы. 1976. Т. 12, вып. 1. С. 93-95.

6. Растительные ресурсы СССР: Цветковые растения, их химический состав, использование; семейства Hydrangeaceae - Haloragaceae. Л., 1987. 152 c.

7. Икрамов М.Т., Мавашева Ф.А., Батиров Э.Х., Маликов В.М. Флавоноиды Lathyrus pratensis // Химия природных соединений. 1990. №2. С. 273-274.

8. Markham K.R. Techniques of Flavonoid Identification. London: Academic Press, 1982. 113 p.

9. Хушбактова 3.А., Файзиева С.Х., Сыров В.Н., Юлдашев М.П., Ботиров Э.Х., Маматханов А.У. Выделение, химический состав и гиполипидемическая активность суммы флавоноидов из Thermopsis alterniflora // Химико-фармацевтический журнал. 2001. Т. 35. №3. С. 35-38.

10. Agrawal P.K., Rastogi R.P. ${ }^{13}$ C-NMR spectroscopy of flavonoids // Heterocyc. 1981. Vol. 16. №12. Pp. 2181-2236.

11. Корулькин Д.Ю., Абилов Ж.А., Музычкина Р.А., Толстиков Г.А. Природные флавоноиды. Новосибирск, 2007. 232 c.

12. Flavonoids. Chemistry, Biochemistry and Application. Ed. Q.M. Andersen, K.R. Markham. New-York: Taylor and Francis Group, 2006. Pp. 869-897. 
Bonacheva V.M. , Drenin A.A., Botirov E.Kh. FLAVONOIDS FROM EQUISETUM ARVENSE L. AND LATHYRUS PRATENSIS L.

Surgut State University, ul. Lenina, 1, Surgut, 628412 (Russia),e-mail: bwmbeml@mail.ru

The article is devoted to the phytochemical study of Flavonoids Equisetum arvense (L.) Smeet and Lathyrus pratensis L. From the overgrown part of Equisetum arvense (L.) Smeet of the first flavonoids luteolin-7-O- $\beta$-D-glucopyranoside, luteolin-4'-O- $\beta$-D-glucopyranoside and elready luteolin isolated. From the overgrown part of Lathyrus pratensis L. luteolin-7O- $\beta$-D-glucopyranoside, luteolin-4'-O- $\beta$-D-glucopyranoside and quercetin-3-O- $\beta$-D-glucopyranoside have been isolated. The resulting compounds were identified on the basis of results of chemical transformations and IR, UV, ${ }^{1} \mathrm{H}-,{ }^{13} \mathrm{C}-\mathrm{NMR}$ and mass spectra.

Keywords: Equisetum arvense L. Smeet, Lathyrus pratensis L. flavonoids, luteolin, luteolin-7-O- $\beta$-D-glucopyranoside, luteolin-4'-O- $\beta$-D-glucopyranoside, quercetin-3-O- $\beta$-D-glucopyranoside.

\section{References}

1. The Science of Flavonoids. Ed. E. Grotewold. New-York: Springer Science, 2006, 273 p.

2. Flavonoids in Health and Disease. Ed. C. A Rice-Evans, L. Packer. New York, 2003, 458 p.

3. Rastitel'nye resursy Rossii i sopredel'nyh gosudarstv. Ch. 1: Semejstva Lycopodiaceae - Ephedraceae. [Plant Resources of Russia and Neighboring Countries. Part 1: Family Lycopodiaceae - Ephedraceae]. St. Petersburg, 1996, pp. 12-15. (in Russ.).

4. Tiktinskij O.D. Urologija i nefrologija, 1983, no. 1, pp. 47-50. (in Russ.).

5. Figurkin B.A. Rastitel'nye resursy, 1976, vol. 12, no. 1, pp. 93-95. (in Russ.).

6. Rastitel'nye resursy SSSR: Cvetkovye rastenija, ih himicheskij sostav, ispol'zovanie; semejstva Hydrangeaceae Haloragaceae. [Plant resources of the USSR: Flowering plants, their chemical composition and utilization; family Hydrangeaceae - Haloragaceae]. Leningrad, 1987, 152 p. (in Russ.).

7. Ikramov M.T., Mavasheva F.A., Batirov Je.H., Malikov V.M. Himija prirod-nyh soedinenij, 1990, no. 2, pp. 273274. (in Russ.).

8. Markham K.R. Techniques of Flavonoid Identification. London, 1982, 113 p.

9. Hushbaktova Z.A., Fajzieva S.H., Syrov V.N., Juldashev M.P., Botirov Je.H., Mamathanov A.U. Himikofarmacevticheskij zhurnal, 2001, vol. 35, no. 3, pp. 35-38. (in Russ.).

10. Agrawal P.K., Rastogi R.P. Heterocyc, 1981, vol. 16, no. 12, pp. 2181-2236.

11. Korul'kin D.Ju., Abilov Zh.A., Muzychkina R.A., Tolstikov G.A. Prirodnye flavonoidy. [Natural flavonoids]. Novosibirsk, 2007, 232 p. (in Russ.).

12. Flavonoids. Chemistry, Biochemistry and Application. Ed. Q.M. Andersen, K.R. Markham. New-York, 2006, pp. 869-897.

Received October 18, 2013

\footnotetext{
* Corresponding author.
} 
